The ercesesion and partivl cesention of fits is thus simply and besutifully described by Dr. Meigs in his forty-fourth Ietter on the Diecases of Women, p. 655. After describing the earlier and outward phenomens of the attack, he goes on to say : "The rapid convulsive movement of the disphragm being accompanied with spasm of the glottis, the blood of the lungs does not receive the benefit of a true and loyal respiration. It does not get its full dose of oxygen, but is hurried aff, imperfectly decarbonated, to the systemic auricle and ventricle, whence it is injected into the brain and the whole system. The darkening hue of the countenance, the deep renous tint of the tongue, and the blueness of the hands and feet, show that the patient is passing into a state of asphyxia; and she does blacken her blood more and more, until the brain no longer receiving oxygen sufficient to extricate the nerve stream, the convulsive innervation ceases, from want of the means to extricate the nerve force, or neurosity, as Dr. Corrie calls it.

"It is also a curious circumstance, and one well worthy of your attention, that the blackening of the blood, or its conversion into venous blood, by the interruption of the respiratory or oxygenating function, should be the means provided and designed by Providence for the cure of the paroxysm. When the whole sanguine mass has become carbonated, the brain and the spinal cord must cease to innervate the muscles convulsively, and the speedy relaxation of every rigid muscle permits the restoration to the lungs of their oxygenating powcr; for, while even the muscular system is convulsed in the spasm, the movement of the mass of the blood is greatly modified by the alternate violent contraction and the relaxation of the muscles-a modification that ceases as soon as the muscles come to a state of rest; so that, in a few moments after the countenance has been black and deformed in every feature, you have the pleasure to sec it recover its whiteness, though ghastly pale; while the brain-I mean the whole brainwakes up to the remewed performance of its organic as well as its intellectual offices. When, therefore, in looking upon these frightful scenes, you see the face of your patient growing darker and darker, you will discover in that very circumstance the hopeful announcement of a speedy close of the distressing exhibition."*

The prognosis in the spinal form of the disease is generally favourable. In the cerebral, when we have to contend with apoplectic mischief, the danger is more imminent, and our opinion must be less propitious. Fortunately, these cases are comparatively rare. Dr. Collins, of Dublin, in his experience, gives 30 cases as occurring to him in 16,414 labours, of which 25 recovered, 5 died. Dr. Churchill has collected tables of 96,903 labours, in which 159 cases of convulsions occurred, giving 1 in 609 .

Now, as to the treatment of this case; all writers, with few exceptions, concur in the necessity and advantage of copious blood-letting, both as a curative means, by lessening the excitability of the spinal system, relieving congestion, and as a preservative of the brain from rupture of some vessel within the cranium; and, accordingly, it has been almost indiscriminately resorted to. Dr. Tyler Smith, I believe, was among the first, if not the first, to lay down some proper directions for our guidance in these trying emergencies. After some very judicious remarks on the effects of blood-letting as a sedative on the spinal marrow, and as a protection to the cerebrum, he goes on to say: "The propriety and extent of venesection must be estimated, not by the violence of the disease, but by the state of the circulation in the intervals of the fits, and with especial reference to the different effects of vascular plethora and vacuity on the spinal marrow. I should avoid these manifest repetitions, had I not thoroughly convinced myself that patients rightly bled in the first instance are frequently subjected to successive depletion, until the loss of blood itself becomes a cause of the final seizures." We did not bleed in this instance. The pulse was quiet; the

- See further, $p .958$, for the beantiful analogy he draws between these convulsire fits and the phenomens of etherisation. face pale; no stertor, or other evidence of vascular congestion. We did not share the head. $A$ few leeches and a cold lotion were applied to the temples, as a guard to the cerebrum ; and, having discovered the distended state of the epigastrium, and believing the cause of the irritation to exist there, we directed our chief efforts to its remoral in the first instance: the history of the case tells with what result.

As to the share which the turpentine giren by the mouth had in effecting the desired relief, I am not sure that we are to ascribe the whole of the merit to it alone. It certainly appeared to act instantaneously, but it is not improbable that the calomel and black draught and the enema may have acted as pioneers to it. At the time, it certainly responded to the train of reasoning in my mind which prompted its suggestion ; namely, its cordial, stimulating, and astringent operations on the mucous surfaces. I had often seen it employed in the wards of the Dublin Lying-in-Hospital, in cases of flatulent distension of the bowels, where it was in my day an established remedy; but in this instance its use was not prompted, though supported by past experience.

A late writer in the Associs riox Joukval recommends the internal use of spirit of turpentine by the mouth, with something of the air of novelty about it; but I believe its introduction to obstetricians, as a remedy for puerperal disease, is due to Dr. Brennan, of Dublin, who wrote a pamphlet on the subject about the beginning of the present century.

The relief obtained at once by the removal of the irritating cause rendered the employment of all other remcdial means unnecessary. Opium, antispasmodics, and chloroform are in certain cases valuable adjurants; but here they were not required, and would have been useless until the exciting cause was removed.

The after treatment of the case requires little comment. The mixtures containing the bicarbonate of potass and liquor opii were intended to soothe and allay the irritation of the bowels after such irritating purgatives; and the slight delirium which arose on the third day, from exhaustion, yielded to a more generous diet and the slight stimulus of brandy and chloric ether.

\section{CASE OF INDENTED SKULL IN A CHILD.}

By S. H. Swayne, Esq., Bristol.

[Read at the Meeting of the Bath and Bristol Branci, April 21th, 1856.] A GIRL, aged 9 months, when being carried by her mother in a public covered van at Minehead, Somerset, on July 15th, 1855, was, by the upsetting of the rehicle, thrown out on the road, and the head of the van fell partly upon her, so that it was obliged to be lifted up before she could be drawn from under it. It was then seen that the side of the child's head and face was much bruised, and a large indentation produced on the crown of the head. Blood was flowing from the mouth, and continued to do so for some time. She seemed quite conscious, and sat up in her mother's arms. She afterwards looked drowsy and depressed, and, in an hour or two later, vomited a quantity of clotted blood. She was taken to a neighbouring medical man, who gave an unfarourable prognosis, but recommended the parents to continue their journey by steampacket to Bristol. As I was absent from home at the time of their arrival, the child was kindly visited for me by $\mathbf{M r}$. Coe. He found a circular depression, with rather rounded edges, about two and a half inches in diameter, and from half to three-quarters of an inch in vertical depth, situated near the posterior superior angle of the left parietal bone, and $s 0$ as to be bounded in front by a line drawn across the vertex from ear to ear. The head looked as if twisted to one side, and greatly disfigured, much of the distortion being no doubt due to swelling.

1 saw the child on the 18th. The swelling and ecchymosis were then diminishing; ohe seemed lively and well; there was no sickness, or any other symptom indicating disturbance of the brain. 
* Prom this time, convalescence proceeded uninterraptedly. The treatment was confined to the application of cold-water pads to the head, and keeping the child quiet. About three months after, she passed through a moderately severe attack of bronchitis, without exhibiting any head symptoms. The depressed bone has by this time risen considerably, and the deformity is much less marked than at first. I anticipate that it will ultimately be quite remored.

Remarks. This case well illustrates the remarkable flexibility of the cranial bones in infancy, permitting such great depression without apparently any complete separation of the sunken portion of bone. It seems probable that the diminished space for the brain is compensated for in these cases by some degree of lateral bulging of the cranial bones. The condition of the sutures also, no doubt, operates to prevent injurious compression taking place. The blood romited proceeded probably from a wound of the mouth.

\section{XIPHISTERNAL OR PERICARDIAL CHISEL- SOUND, WITI ITS PRACTICAL APPLICATION.}

By Frederick Janes Browa, M.D., Chatham, Kent. [Real before the Medical Society of Lonilon, April 5th, 1856.] [Concluded from page 385.$]$

Case IV. Mr. Henry B., aged 19 years, railway clerk, visited by me at Chatham, 14th March, 1854. He had just come from Red Hill station, in Surrey, where he had been ill one month. He had been treated for nerrous disorder with palpitation. Symptoms and Signs.-Mobile nervous system; lateral curvature of the spine; mind and body orcrworked in his duties on the railway; insomnia; pallor; great nervous susceptibility; palpitation; tongue whitish; pulse 86 , firm; no headache; cardiac dulness normal; chisel-sound heard all along the sternum; deficiency of respiration under the right clavicle. He had not expericnced benefit from the treatment addressed to the nerrous system whilst he was in Surrey. He was now placed on cardiac treatment. In two days the whiteness of the tongue and the insomnia disappeared. On the 28th March, he was seized with catching respiration, and other symptoms of spinal irritation. He was better on the 6 th April, and was then ordered cod-liver oil. On the 15th, he was much better, and was soon after discharged cured; but the chisel-sound, although greatly diminished, was discernible at the lower end of the sternum.

CASE v. Miss B., aged 17 years, sister to the young man whose case precedes this, had been ill six weeks with palpitation when seen by me on the 8th October, 1854 . Symptomis and Signs.-Pain in the cardiac region, with palpitation; chisel-sound at the lower end of the sternum; slight lateral curvature of the spinc.

On the 16th October, she had symptoms of spinal irritation. On the 24th she was much better, and soon after recovered. The chisel-sound did not wholly disappear. No leeches or blisters were employed, but the pills and mixture only.

February 7th, 1855, she was readmitted on my list, suffering from pain and palpitation. The chisel-sound was audible. Blisters were used, with medicines internally, but very little improvement occurred until counter-irritation to the spine was employed. The cardiac pain and the palpitation ceased. The chisel-sound continues.

This patient is under treatment at the present time.

Case vi. Complication with Hypertrophy. Richard A., of middle age, a mariner, was visited by me in Rochester, in June 1854. He suffered from cardiac pain in 1852 . There was chisel-sound detected in his case at that time. He was treated for it and relieved. He has complained occasionally of cardiac pain since the attack in 1852.

When I saw him in June 1854, he was suffering from mild subacute pericarditis. He soon recovered under appropriate treatment, but subsequent examination showed extended cardiac dulness, hearing, strong impulse, and chisel-sound.

CasE vir. Complication with Hypertrophy. Edwin McG., a lad, about 17 years of age, was visited by $m e$ in Rochester, 13th May, 1853. He had scarlatina, succeeded by dropsy, five years previously. The friends state that the heart was then affected. He appliod to me for enlargement of the tonsils, and made no complaint of cardiac pain, or of palpitation. The strumous habit was strongly marked. Physical signs.-Cardiac dulness considerably extended; heaving, forcible impulse; chisel sound at lower end of sternum. The asperity of the sound diminished under repeated small leechings and blisterings, with the use of medicinc. He has had several attacks of pain, with temporary increase of the roughness of the chisel-sound, since MIay 1853.

CASE viII. Complication with Hypertrophy. William G., a lad, about 18 years of age, was visited by me in Rochester, 6th July, 1854. Physical signs.-Cardiac dulness extended; impulse heaving; chisel-sound. This lad had two inflammatory attacks within eighteen monthsboth of them previously to my visit in July.

Case 1x. Complication with Subacute Rhermatism. Henry H., aged 36 years, pipe maker, was visited by me at Chatham, 1jth March, 18j4. He was subject to rheumatism, and was labouring under the disease in a subacute form when seen by me. He complained of uneasiness in the left side, but felt no pain. Had no cough, dyspnoea, or palpitation. No valvular murmurs. Chisel-sound was audible at the lower part of the sternum. This patient was soon relieved by treatment.

CASE x. Complication with Phthisis. Mrs. B., aged 33 years, was visited by me at Chatham, 10th January, 1852. She was in the third stage of phthisis. Cardiac Symptoms and Signs.-Pain under the left breast. Cardiac impulse augmented; chisel-sound audible. She was relieved by treatment in a few days.

CASE xr. Complication with Eicthyma, Chorea, and Rhermatism. Alice M., aged 11 years, was visited by me at Chatham, 28th February, 1853. The chisel-sound was audible. Iron only was given, aud the child soon recovered. The chisel-sound continues.

CaSe xIr. Complication with Hypochondriasis. Mrs. S., nearly 70 years of age, was visited by me at Chatham, 10th July, 1854. The chisel-sound was audible. The patient was greatly relieved, and the asperity of the sound was diminished, by treatment.

CASE XIII. Complication with Tuberculosis and Ovarian Disorder. Susannah S., aged 24 years, a domestic servant, residing in Rochester, was visited by me on the 9th April, 1854. She had cardiac pain and chisel-sound. She, récovered in a few months under treatment addressed to the cardiac and ovarian regions, together with the use of codliver oil and sulphuric acid. This young woman is, at the present time, in confirmed phthisis. I have not had an opportunity of examining her heart, as she has removed from her former residence.

CASE xIV. Conplication with Cerebral Affection and Ovarian Disorder. Miss C., of middle age, of Maidstone, was visited by me in a village near Chatham, 19th July, 1854. History.-Had a paralytic fit ten or twelve years since. Has been affected ever since with vertigo, tinnitus, stupified feeling, burning of eye-balls, spasm of cesophagus, smarting and fluttering in the region of the heart, and nervous dread. The catamenia occur every five weeks. Physical signs.-Cardiac impulse augmented; chisel-sound audible. This patient was only a few weeks under treatment, but in that time considerable improvement took place.

CAsE xV. Complication with Cerebral Affection and Hypochondriasis. Stephen H., aged 43 years, seaman, was seen by me at Chathaw, 4th June, 1854. He had a paralytic fit a few years since. He was suffering from headache and vertigo, also from hypochondriasis. Cardiac dulness normal; no pain in cardiac region; chisel-sound sudible. This man went to sea after the single visit. 